\title{
A transdisciplinaridade em perspectiva
}

Se os periódicos reservassem um terço de seu espaço textual para abrigar artigos de cunho transdisciplinar, isso poderia resultar em quê? Na quebra do paradigma positivista, responsável pelo fracionamento das disciplinas científicas em fins do século XIX? Na ampliação do diálogo e debates entre campos de conhecimento correlatos, como os que se reúnem nas chamadas Ciências Sociais Aplicadas? Na redução da excessiva especialização que frequentemente passa ao largo dos temas mais cruciais do nosso tempo? Na adoção de um novo padrão cultural, mais ecumênico, democrático e menos corporativo?

Às vezes tem-se a impressão de que estamos regredindo, em alguns aspectos, para um curioso "corporativismo de ofício" em plena pós-modernidade. Isso pode ser resultado da excessiva competitividade derivada das normas básicas que regem a produção científica no mundo inteiro, inclusive as que vêm predominando nas decisões de comitês de áreas da Capes e do CNPq. Nesse âmbito, teriam mais liberdade intelectual os cursos que se autointitulam interdisciplinares? Ou estariam apenas exercendo um senso de oportunidade, já que da interdisciplinaridade até a transdisciplinaridade há um bom caminho a percorrer?

A demografia, vista historicamente, estabeleceu vínculos mais ou menos intensos com disciplinas tais como Economia, Estatística, Sociologia, Antropologia, Etnologia, História, Geografia, Biologia, Medicina, entre outras. Esses vínculos na atualidade arrefeceram-se diante da excessiva especialização nos marcos da demografia formal? A quantas anda a demografia substantiva, nicho onde a transdisciplinaridade pode avançar?

É evidente que essas considerações não propõem a liquidação dos modelos e técnicas de mensuração, o que seria pura insensatez. Daí a formulação do um terço constante na pergunta inicial. A modelagem e os métodos quantitativos avançados são necessários, embora limitados, tanto quanto a famosa teoria dos jogos ou a teoria de Malthus. As curvas exponenciais, as proporções aritméticas e geométricas da população e dos recursos magnetizam as atenções de autoridades governamentais do mundo inteiro até hoje, especialmente quando se leva em conta o pequeno lapso de tempo que evoluímos dos seis aos sete bilhões de habitantes atuais. A insepulta ameaça da fome passa a ser rediscutida, tendo como parâmetros: o problema do desenvolvimento durável e das mudanças ambientais; os limites do desenvolvimento no capitalismo global diante de novos padrões de consumo; e a disseminação do estilo de vida ocidental vis-à-vis as implicações do extraordinário crescimento econômico da China.

Parte das questões aqui lançadas passa por novas formas de pensar a noção de equilíbrio e complexidade, porquanto equilíbrio também diz respeito a fatores de estabilidade de gêneros de vida do passado ou ao que se espera dos impactos da modernização nos objetos e nas pessoas do presente. Assim, passam a usufruir de novos direitos as tantas populações tradicionais que insistem em conservar tradições com pouca capacidade de adaptação a mudanças. Do lado da complexidade, o convívio entre o tradicional e o moderno é um tema intrincado, pouco explorado e alude a processos evolutivos de múltiplas facetas, às vezes inexoráveis, multiescalares, que podem dar origem: à tão decantada, mas pouco aprofundada, "fragmentação territorial" da atualidade - como se fosse um mal que se deve evitar -; ou a numerosos 
lugares antigos tidos como estagnados, onde os investimentos do desenvolvimento econômico, ao envolvê-los, os alteram significativamente, não raro sem a consciência das consequências entre os atores, ou mesmo sem o controle planejado dos agentes. Essas questões dizem respeito a qualquer disciplina que estude populações, espaço e recursos.

$\mathrm{Na}$ demografia são muitas as possibilidades de se trabalhar com questões complexas e transdisciplinares, de modo a introduzir novas leituras do presente e lançar luz na compreensão de conflitos renitentes que se metamorfoseiam ou se dissipam, dando origem a outro cenário de problemas no futuro próximo ou distante. Os dez tópicos abaixo tentam agregar parte de um amplo elenco de questões que os estudos demográficos podem abarcar: 1) implicações culturais, econômicas e ambientais do crescimento zero; 2) conflitos regionais resultantes do envelhecimento da população diante das necessidades de mão de obra contrastadas com de práticas de xenofobia em países ricos; 3 ) mitigação da pobreza e uso legal da força de trabalho de famílias e indivíduos em países de destino; 4) melhoria ou piora do padrão de vida como resultado de modelos predatórios de desenvolvimento; 5) contribuições da migração para a redução de desigualdades sociais na contemporaneidade; 6) mudanças da fecundidade e mortalidade e padrões de vida no Ocidente e no Oriente; 7) significados de políticas públicas que impactam direta ou indiretamente populações regionais ou sub-regionais; 8) questões associadas a população, recursos e crises sistêmicas do capitalismo mundial; 9) imbricações das redes migratórias com as redes econômicas globais; 10) formação de redes transfronteiriças da migração internacional na América do Sul, significados e relações de custo-benefício.

Esse decálogo pode se estender a muito mais combinações de temas capazes de avaliar dinâmicas populacionais em áreas de guerra e paz da atualidade, ou que considerem o declínio da mortalidade e fecundidade em grandes regiões do planeta, mas sem perder de vista as intercessões entre pobreza, desigualdade e desenvolvimento econômico em ambientes rurais e urbanos, assuntos que não são estranhos à Revista Brasileira de Estudos de População (Rebep).

Aliás, vale dizer, a Rebep, em termos de organização e agilidade, muito progrediu nos últimos anos, embora as possibilidades de refinamento sejam múltiplas e abertas. Afinal, como manter seu nível de qualidade aumentando sua interlocução científica?

A transdisciplinaridade ante os temas atuais é uma perspectiva promissora, uma vez que pode incorporar os avanços técnicos e metodológicos em áreas de ênfase da revista, tais como mortalidade, natalidade, migrações, nupcialidade, transição demográfica e envelhecimento da população. Contudo, mesmo considerando a profusão de estudos que incorporaram as dinâmicas inscritas na distribuição e redistribuição da população em espaços internacionais, regionais, urbanos e rurais, ou as pesquisas sobre mudança climática, população e meio ambiente, falta maior correlação entre esses temas e os impactos que se anteveem na trajetória da economia mundial. Inclusive porque, a despeito do incremento das tecnologias poupadoras de mão de obra, a incessante expansão do setor de serviços continuará ampliando, em muito, a demanda de força de trabalho no futuro, mesmo que se refira a populações ativas minimamente qualificadas. Mas, se assim for, para onde vão os estoques de população jovem não qualificada ávida por trabalho?

Enfim, a complexidade dessas questões pode ser enfrentada de diversas formas, ao se pensar em uma revista científica de população. Servem de exemplos os incentivos a números temáticos especiais, a valorização de coautorias de profissionais de extração variada e de ensaios e artigos teoricamente abrangentes, talvez porque uma questão substantiva básica diga respeito à expansão da dialogicidade como método, mesmo que as certezas sejam mais ou menos provisórias como nos sugere o paradigma da dúvida formulado por Sócrates. A dúvida deveria ser um procedimento eurístico usual, que, inclusive, auxiliasse a estabelecer perguntas mais qualificadas sobre o futuro do crescimento demográfico mundial e a crise econômica e sociocultural que nos atinge a todos.

Esse número da Rebep traz alguns blocos de artigos temáticos, não obstante a variação e diversidade existente entre eles. Três textos se apresentam no campo da mortalidade. $\mathrm{O}$ primeiro, "Diferenciais de mortalidade: níveis e padrões segundo o sexo no município de São 
Paulo de 1920 a 2005", de Pamila Siviero, Cássio Turra e Roberto Nascimento Rodrigues, contém uma análise com base na contribuição de homens e mulheres em diversas idades sob o hiato na esperança de vida ao nascer. As conclusões, após o exame da razão de sexo e taxas específicas de mortalidade, explicitam o processo tardio de transição do padrão etário da mortalidade diferencial, a redução dos diferenciais pelo declínio da mortalidade masculina nas idades jovens e a sugestão de que o comportamento futuro dos diferenciais de mortalidade por sexo dependerá da heterogeneidade no risco de morrer em idades avançadas. $O$ segundo texto, "A evolução do sub-registro de mortes e causas de óbitos mal definidas em Minas Gerais: diferenciais regionais", de Everton Lima e Bernardo Lanza Queiroz, combina técnicas de demografia formal com técnicas de análise espacial. Os autores concluem que houve melhoria na cobertura de mortes entre 1980 e 2007, a despeito do aumento das causas mal definidas, sobretudo em subespaços do norte e nordeste de Minas Gerais. Já o artigo "La reducción de la mortalidad infantil desde un enfoque de derechos: una comparación entre Argentina y Brasil", de María Marta Pizzarro e colaboradores, trata das obrigações, avanços e retrocessos no exercício dos direitos, nos marcos de políticas governamentais desenvolvidas a partir de 1990. Apesar da relativa escassez de informações, os resultados evidenciam que houve significativas reduções nas taxas de mortalidade infantil, embora insuficientes quando se consideram as prescrições internacionais, especialmente no que diz respeito ao cumprimento do princípio da igualdade e não discriminação.

Quatro outros artigos abordam circunstâncias e condições ambientais e de desenvolvimento que afetam populações em diferentes contextos de moradia e trabalho. Em "As amenidades naturais influenciam a escolha locacional dos trabalhadores? Evidências para as regiões metropolitanas brasileiras", Roberta Rocha e André Magalhães mostram a influência de características naturais de grandes metrópoles nas decisões locacionais dos trabalhadores. Com base no modelo de escolha locacional de Roback, eles concluem que os trabalhadores manifestam preferência em morar em metrópoles costeiras mais úmidas, onde são maiores as temperaturas no mês de janeiro, em comparação com outras metrópoles onde são maiores os índices de precipitação em setembro e as temperaturas médias de julho. $\mathrm{O}$ artigo de Ricardo Ojima, "As dimensões demográficas das mudanças climáticas: cenários de mudança do clima e as tendências do crescimento populacional", focaliza a importância das mudanças climáticas na atualidade, em termos socioeconômicos, político e demográfico. $\mathrm{O}$ autor exorta as ciências do clima e a demografia para desenvolverem esforços interdisciplinares nessa área emergente de estudos e procura expor argumentos a favor de um deslocamento do tema da arena ambientalista para uma espécie de demografia sintonizada com as mudanças climáticas. No texto "Von Thünen e o abastecimento madeireiro de centros urbanos pré-industriais", Diogo Cabral aborda a economia madeireira em um contexto pré-industrial da cidade do Rio de Janeiro, momento no qual a madeira era um recurso natural indispensável como material construtivo e fonte energética. $\mathrm{O}$ artigo discute limitações da teoria de Von Thünen (efeito da distância do mercado sobre a produção agrária) e utiliza-se de exemplos históricos para formular um modelo teórico-conceitual em que a atividade madeireira responde às variações da intensidade agrícola. O último artigo nesse eixo temático é de Gavin Jones e focaliza relações entre desenvolvimento e população (population and development).

Dois outros artigos trabalham com populações tradicionais do Brasil. O de Pery Teixeira, Marília Brasil e Eliana Silva, "Demografia de um povo indígena da Amazônia brasileira: os sateré-mawé", traz resultados de um levantamento sociodemográfico participativo realizado entre 2002 e 2003 sobre a população sateré-mawé do oeste do Estado do Amazonas. O estudo conclui que a estrutura etária é de uma população de alta fecundidade, alta mortalidade infantil e baixo estoque de idosos, com intensos fluxos migratórios entre terras indígenas e, mais recentemente, em direção a cidades vizinhas. O artigo "Classificação dos domicílios 'indígenas' no Censo Demográfico 2000: subsídios para análise das condições de saúde", de Gerson Marinho e colaboradores, procura caracterizar domicílios indígenas - coletivos ou "improvisados" - em termos de condições de saneamento, habitação e perfil socioeconômico 
em territórios do Mato Grosso do Sul e do Centro-Oeste. As análises indicam a necessidade de aprimorar a forma de captação da informação censitária, tendo em conta a diversidade étnica e a relativa "invisibilidade demográfica e epidemiológica" dos povos indígenas. Com isso, o enfrentamento das desigualdades no âmbito da saúde dessa importante fração da população brasileira poderia avançar significativamente.

Outro bloco exibe dois textos que se dedicam a tecer considerações metodológicas sobre técnicas e modelos utilizados mundialmente em estudos demográficos. O primeiro, de Raquel Guimarães e Eduardo Rios-Neto, intitulado "Comparação entre metodologias idade-período-coorte para o estudo de uma medida de progressão escolar no Brasil", detém-se em estimadores convencionais, a fim de verificar mudanças temporais na probabilidade de progressão para a 5 ${ }^{a}$ série do ensino fundamental das mulheres brasileiras. Os parâmetros foram contrapostos em termos da eficiência e significância, e os resultados revelam as potencialidades do modelo IPC (baseado no estimador intrínseco), diante da variância inferior aos estimados pelo modelo linear generalizado restrito. O segundo artigo, de Gilvan Guedes e colaboradores, intitulado "Incorporando a variabilidade no processo de identificação do modelo de máximo global no Grade of Membership (GoM): considerações metodológicas", explora o uso de análises multivariadas sobre bases de dados complexas nas áreas de saúde e ciências sociais, focalizando questões relativas à identificabilidade e estabilidade dos parâmetros-chave do modelo GoM 3,4. Determinadas limitações do modelo de Máximo Global (MG) com parâmetros estáveis são contornadas mediante o uso do Máximo Global Ponderado (MGP), indicador que suaviza situações em que desvios médios são muito pequenos.

Ao final, a revista traz aos leitores relatos sobre livros e pesquisas recentes nas seções "Notas de Pesquisa" e "Resenhas". Ernesto Amaral resume pesquisa intitulada "Análise do nível, padrão e determinantes dos fluxos populacionais entre Bahia e São Paulo" e Gilvan Ramalho Guedes, Pamila Siviero e Carla Jorge Machado comentam pesquisa que focaliza "Aspectos práticos na identificação de um modelo de Grade of Membership de máximo global: o uso da moda das probabilidades estimadas". Em "Contemporaneidade, escalas e lugares - panoramas dos estudos de população e ambiente na atualidade", Thais Tartalha faz um amplo resumo do livro Dinâmicas demográficas e ambiente, organizado por D’Antona e Carmo. Paula Miranda-Ribeiro, por sua vez, apresenta a instigante resenha "Encontro marcado entre a demografia e a religião", referente ao livro organizado por Ellison e Hummer, Religion, families and health.

Ralfo Matos

Doutor em Demografia. Professor associado do Instituto de Geociências - IGC/UFMG. 